\title{
DIREITO À SAÚDE: A JUDICIALIZAÇÃO DA CONCESSÃO DE MEDICAMENTOS DE ALTO CUSTO
}

\section{ARTIGO ORIGINAL}

MACÊDO, Karen Vanderlei ${ }^{1}$

MACÊDO, Karen Vanderlei. Direito à saúde: A judicialização da concessão de medicamentos de alto custo. Revista Científica Multidisciplinar Núcleo do Conhecimento. Ano 05, Ed. 12, Vol. 07, pp. 05-16. Dezembro de 2020. ISSN: 24480959, Link de acesso: https://www.nucleodoconhecimento.com.br/lei/direito-a-saude

\section{RESUMO}

O objeto de análise deste artigo é o entrelaçamento entre o direito à saúde no Brasil e o acionamento do Supremo Tribunal Federal (STF) como garantia de efetividade prática, a judicialização da política, em especial, a concessão de medicamentos de alto custo. Perante o direito à saúde no Brasil dois Princípios entram em colisão, o da reserva do possível e o do mínimo existencial, que requer de acordo com Barroso (2009) uma ponderação por parte do intérprete da lei sobre a razoabilidade dos casos específicos. Para verificar, no que se pauta o direito à saúde, analisamos alguns Acórdãos do STF sobre a matéria, que constam em seu site. Observamos que há nas decisões do STF uma preponderância da reserva do possível em detrimento do mínimo existencial.

Palavras-Chave: Constituição Federal, Direito à Saúde, Medicamentos de Alto Custo, Princípio da Reserva do Possível.

${ }^{1}$ Graduação em Direito (Estácio CEUT), Especialização em Gestão Pública com ênfase em licitação de contratos (FAR); Especialização em Direito Público (FAR, em andamento) e Mestrado em Direito Público (Universidade Portucalense, em andamento). 


\section{INTRODUÇÃO}

O nosso objeto de análise é o entrelaçamento entre o direito à saúde no Brasil e o acionamento do Supremo Tribunal Federal (STF) como garantia de efetividade prática, a judicialização da política. De forma mais específica, versa sobre a determinação compulsória de fornecimento de medicamentos de alto custo a partir das decisões proferidas pelo Supremo Tribunal Federal.

Esse tema se faz urgente, em particular, quando o Conselho Nacional de Justiça (CNJ), por meio do seu "Justiça em Números" de 2018 (último relatório publicado no sítio do CNJ, porém referente ao ano base de 2017), demonstra que houve 1.346.931 demandas judiciais no que diz respeito a natureza diversa do que abrange o direito à saúde. De acordo com Sarlet (2018, n.p.) "[...] os gastos da União com ações judiciais envolvendo prestações de saúde cresceu na ordem de $727 \%$ entre 2010 e final de 2016, quando alcançou a cifra de $\mathrm{R} \$ 3,9$ bilhões". O ano de 2016 é emblemático, pois foi o ano em que iniciou a tramitação do Recurso Extraordinário (RE) 657718, com repercussão geral reconhecida, de relatoria do ministro Marco Aurélio, que teve o seu desfecho em 22 de maio de 2019.

O RE 657718, teve como epicentro o julgamento decorrente ao fornecimento de medicamentos de alto custo pelo poder público, especialmente, os que não constavam na lista do Sistema Único de Saúde (SUS), assim como os que não tivessem registro junto à Agência Nacional de Vigilância Sanitária (ANVISA). Com o desfecho em maio de 2019, o STF tomou algumas decisões que regulamentam a concessão compulsória de medicamentos.

As decisões foram para apaziguar a relação entre o direito à saúde e o orçamento do Estado. De acordo com o Ministro Roberto Barroso "não se trata de negar direito fundamental à saúde. Trata-se de analisar que a arrecadação estatal, o orçamento e a destinação à saúde pública são finitos" (STF, 2019, n.p.). Essa decisão vai de encontro com o Princípio da Reserva do Possível e com as decisões recentes sobre o orçamento brasileiro, em particular a aprovação no ano de 2016 da Proposta de Emenda Constitucional 241, numerada no Senado como 55, que prevê o 
congelamento dos gastos públicos, que pode entrar em colisão com o Princípio do Mínimo Existencial.

A decisão foi tomada, por maioria de votos, no julgamento do Recurso Extraordinário (RE) 657718, com repercussão geral reconhecida, de relatoria do ministro Marco Aurélio, e fixou a seguinte tese: 1 - o Estado não pode ser obrigado a fornecer medicamentos experimentais; 2 - a ausência de registro na Anvisa impede, como regra geral, o fornecimento de medicamento por decisão judicial; 3 - é possível, excepcionalmente, a concessão judicial de medicamento sem registro sanitário, em caso de mora irrazoável da Anvisa em apreciar o pedido (prazo superior ao previsto na Lei 13.411/2016), quando preenchidos três requisitos, quais sejam: I) a existência de pedido de registro do medicamento no Brasil, salvo no caso de medicamentos órfãos para doenças raras e ultra raras; II) a existência de registro do medicamento em renomadas agências de regulação no exterior; III) a inexistência de substituto terapêutico com registro no Brasil. Por fim, o STF ainda decretou que, 4 - as ações que demandem o fornecimento de medicamentos sem registro na ANVISA deverão ser necessariamente propostas em face da União (STF, 2019).

Dessa maneira, em pormenores, este artigo busca identificar se durante o trâmite do RE 657718 o Estado brasileiro já se comportava de modo a negar os pedidos de concessão compulsória de medicamentos que não tinham registro na ANVISA e/ou estavam fora da lista do SUS. O que se questiona é: o comportamento do STF em relação a concessão compulsória de medicamentos antes do desfecho do RE 657718 mostrava-se contra ou a favor a liberação de medicamentos que estavam fora da lista do SUS e não tinha registro da ANVISA?

A nossa hipótese é que o Princípio da Reserva do Possível pode ter influenciado as decisões do STF no que tange à concessão de medicamentos considerados de alto custo, em particular, os que não se encaixam na decisão proferida em maio de 2019.

Para verificar o comportamento do STF em relação à concessão ou não de medicamentos considerados de alto custo, observamos os acórdãos que foram proferidos pela Corte Suprema no período de 2017 a 2018 (intervalo temporal entre o 
início e o fim do Recurso Extraordinário já citado). Esses Acórdãos estão disponíveis no site do STF e foram analisados todos que se deram nesse intervalo temporal, ao todo foram 15.

A nossa principal preocupação em relação aos dados contidos nos Acórdãos era o de analisar a resposta proferida pelo STF. Tal informação nos deu condições de analisar o que guiou de fato as decisões judiciais proferidas pela Suprema Corte no que diz respeito ao fornecimento de medicamentos de alto custo, como consta nas nossas considerações finais.

Neste artigo, em primeiro lugar, iremos tratar sobre o direito à saúde, assim como a sua judicialização. Em seguida, iremos demonstrar os argumentos que circundam o debate entre o Princípio do Mínimo Existencial e o Princípio da Reserva do Possível, para, em terceiro lugar, analisar o comportamento do STF a partir dos Acórdãos contidos no site do STF.

\section{DIREITO À SAÚDE NO BRASIL: A CONCESSÃO DE MEDICAMENTOS E A SUA JUDICIALIZAÇÃO}

O sistema de saúde do Brasil é financiado por uma série de impostos nos níveis Federal, Estadual e Municipal. Os Estados recebem dinheiro do Governo Federal, enquanto os Municípios recebem financiamento dos governos Federal e Estadual. Além disso, a priori, o governo sempre se comprometeu a cobrar impostos, aumentálos e até mesmo aproveitar as receitas do petróleo do estado para financiar o Sistema Único de Saúde (SUS).

Este esforço reflete uma longa história de compromissos sociais e políticos para fornecer serviços de saúde pública. Depois de obter a independência de Portugal em 1822, o Brasil viu o surgimento de movimentos sociais bem organizados defendendo a intervenção do Estado nos cuidados de saúde.

Apoiados por impostos sobre a renda pessoal (Imposto de Renda Pessoa Física) e a Previdência Social, as autoridades de saúde concordaram com esses movimentos em 
que a assistência médica era uma responsabilidade do Estado e que todos deveriam contribuir para o sistema. Essa política sobreviveu a governos democráticos e autoritários ao longo do século $\mathrm{XX}$, perdurando até a transição para a democracia em 1988. Também foi sustentada com a ajuda de movimentos sociais proativos de saúde, como os sanitaristas, compostos de médicos, burocratas e políticos.

Essa ideia de responsabilidade compartilhada na prestação de serviços de saúde era tão popular que acabou se tornando parte da constituição de 1988. Através da introdução do SUS pela constituição, a assistência à saúde tornou-se uma responsabilidade oficial do Estado e um Direito Humano, uma questão sobre a qual liberais e conservadores poderiam concordar.

Dessa forma, o direito à saúde no Brasil é um direito social, que consta como preceito constitucional, em particular, no Art. 6., na redação atribuída pela Emenda Constitucional n. ${ }^{\circ}$ 90/2015, que preceitua: "são direitos sociais a educação, a saúde, a alimentação, o trabalho, a moradia, o transporte, o lazer, a segurança, a previdência social, a proteção à maternidade e à infância, a assistência aos desamparados, na forma desta Constituição" (BRASIL, 2019, n.p.). Sendo assim, enquanto direito social cabe ao Estado brasileiro agir a partir de políticas sociais para que os cidadãos sejam atendidos de forma efetiva, especialmente, no que tange à saúde.

A saúde como um dever estatal que se faz por meio de políticas sociais é amparada na Constituição Federal de 1988, no Art. 196, que preceitua:

a saúde é direito de todos e dever do Estado, garantido mediante políticas sociais e econômicas que visem à redução do risco de doença e de outros agravos e ao acesso universal e igualitário às ações e serviços para sua promoção, proteção e recuperação (BRASIL, 2019, n.p.).

Dessa forma, observa-se que a saúde deve ser garantida enquanto um direito social por meio de políticas sociais e que é de dever do Estado.

De acordo com Vasconcelos Filho (2010), a efetivação dos direitos sociais está diretamente relacionada com a intervenção do Estado, especialmente, por meio de 
políticas sociais. O direito à saúde é exemplo de direito social com titularidade individual, correspondendo às suas necessidades básicas não apenas para existência física, mas psíquica e moral.

Os dois artigos supracitados, o Art. 6. e Art. 196, asseguram aos cidadãos brasileiros os direitos sociais e a sua efetividade por meio das políticas sociais, uma novidade e um avanço, no que concerne a ampliação de direitos democráticos, em relação ao regime autoritário anteriormente estabelecido no Brasil entre 1964 e 1988. Assim, cabe aos cidadãos desfrutarem de tais direitos, em especial, do direito social à saúde que possibilita aos cidadãos uma vida digna e saudável, em tese por meio do SUS.

O SUS é administrado pelos governos Federal, Estadual e Municipal. Os municípios prestam serviços de saúde, os estados coordenam as ações de saúde e o governo federal regula e financia o sistema. O SUS foi um passo relevante na descentralização da atenção à saúde no Brasil, pois também estabeleceu os critérios para distribuição de recursos entre estados e municípios. Na década de 1990, houve maior descentralização da atenção à saúde, por meio das Normas Operacionais Básicas (NOB-SUS). Desde então, o encargo financeiro da provisão direta de bens e serviços de saúde é em grande parte transportados por estados e municípios brasileiros (RIBEIRO, 2013). Um exemplo de prestação de serviços de saúde pública, que faz com que o direito à saúde seja cumprido é a distribuição gratuita de medicamentos.

A Política Nacional de Medicamentos, criada em 1998, dita planos, programas e atividades relacionadas à assistência farmacêutica para todos os níveis de governo (federal, estaduais e municipais). A política veio na sequência de um diagnóstico de "fornecimento de medicamentos desequilibrado, no nível ambulatorial", o que foi considerado por ter um impacto negativo nos cuidados de saúde. A política determina que o Ministério da Saúde atualiza continuamente a Relação Nacional de Medicamentos Essenciais, que define quais medicamentos são fornecidos gratuitamente no sistema público de saúde. Estes são os "considerados básicos e indispensáveis para abordar a maioria dos os problemas de saúde da população (BRASIL, 2001). 
A política de assistência farmacêutica também é descentralizada. A Lista Nacional de medicamentos, que é baseada no perfil epidemiológico regional, forma a base para a organização dos estados e municípios. Os Estados e Municípios são os responsáveis pelo financiamento desses medicamentos e também pela entrega da medicação incluída nas três listas (nacional, estadual e municipal).

Os direitos sociais, em especial, o de saúde não se faz de forma automática. A efetividade dos direitos sociais enfrenta muitos desafios, para além da legalidade expressa na Constituição Federal, há, de acordo com alguns estudos, uma realidade que se faz distante da "letra fria da lei", isto é, o distanciamento entre norma constitucional e a prática efetiva é uma realidade brasileira (RIBEIRO, 2013; VIEIRA, 2008; HOIRISCH, 2010; VALLE; CAMARGO, 2011). Esse distanciamento entre norma e prática tem ido de encontro como o Art. 5.- , no seu inciso XXXV, onde preceitua que: "a lei não excluirá da apreciação do Poder Judiciário lesão ou ameaça a direito" (BRASIL, 2019, n.p.). Assim, a não efetivação de direitos sociais, em especial, o da saúde, que é o nosso objeto de estudo, está propícia a passar por uma judicialização da política, em que consiste em provocar o Poder Judiciário a tomar um posicionamento no sentido de garantir a lei, na maioria das vezes, obrigando a União, Estados e Municípios a cumprirem os textos legais.

No Brasil, a judicialização dos cuidados de saúde é usada para descrever a afirmação judicial do direito positivo constitucional à saúde por indivíduos que não podem obter bens e serviços do sistema público de saúde. Este nível de judicialização dos cuidados de saúde só é possível porque a Constituição de 1988 adotou um sistema de forte revisão judicial dos direitos individuais. Além de garantir um direito individual à saúde, a Constituição Federal também obriga o Estado a criar e manter um sistema de saúde universal, o SUS (Lei n.. 8080/1990).

Na grande maioria dos casos, o governo é obrigado a cumprir ordens judiciais, mesmo que elas não façam parte do plano da administração. Isso tem dois efeitos no sistema: o impacto das decisões na alocação de recursos orçamentários no sistema público de saúde e na gestão da própria assistência farmacêutica. Tais efeitos recaem principalmente nos estados e municípios, porque são os provedores dos principais 
bens e serviços de saúde ordenados pelos tribunais. Na tentativa de recuperar o controle sobre os gastos orçamentários e a gestão da assistência farmacêutica, houve relatos de uma grande variedade de intervenções na política de saúde do Brasil. As intervenções surgem, especialmente, das decisões tomadas pelo STF, no intuito de condicionar o comportamento dos magistrados brasileiros em relação à concessão de direitos à saúde, a exemplo do caso dos medicamentos.

Uma dessas intervenções é a RE 657718, que teve o seu início em 2016 e o seu desfecho em 2019. As recomendações vão de encontro a regulamentar, a partir de uma Repercussão Geral, o comportamento dos magistrados no que tange à concessão de medicamentos de alto custo. No fim das contas, o Poder Judiciário, por meio do STF, implementa uma receita para contenção de gastos públicos que vai de encontro com o Princípio da Reserva do Possível.

\section{PRINCÍPIO DA RESERVA DO POSSÍVEL: A SUA INTERFERÊNCIA NO DIREITO À SAÚDE (UM MÍNIMO EXISTENCIAL)}

O fornecimento de medicamentos de alto custo aos cidadãos brasileiros faz jus a uma análise dicotômica: uma focada no Princípio da Reserva do Possível e outra na perspectiva do Princípio do Mínimo Existencial, que por sua vez vai de encontro com o Princípio da Dignidade da Pessoa Humana. Deve-se inquirir a possibilidade de solucionar os problemas da realidade a serem enfrentados, isso alicerçada na ponderação dos valores ou direitos envolvidos, baseados nos postulados da razoabilidade e da proporcionalidade na conjuntura do Estado Democrático de Direito Brasileiro, nos termos delineados por Alexy (2008).

Os princípios, de acordo com o Ministro Barroso (2009, p. 8), "abrigam um direito fundamental, um valor, um fim. Ocorre que, em uma ordem jurídica pluralista, a Constituição abriga princípios que apontam em direções diversas, gerando tensões e eventuais colisões entre eles". Ainda de acordo com o Ministro do Supremo Tribunal Federal, nesses casos de colisão não podemos partir para o "tudo ou nada", mas cabe ao intérprete da lei analisar cada caso, e assim atuar à ponderação entre princípios e fatos relevantes. 
Essa discussão traduz-se em um entendimento do magistrado em casos individualizados ou ainda em um modelamento da decisão do magistrado em casos de Repercussão Geral, definidos por maioria do STF. O importante nessa tese é que, de acordo com Barroso (2009, p. 12),

Sempre que a Constituição define um direito fundamental ele se torna exigível, inclusive mediante ação judicial. Pode ocorrer de um direito fundamental precisa ser ponderado com outros direitos fundamentais ou princípios constitucionais, situação em que deverá ser aplicado na maior extensão possível, levando-se em conta os limites fáticos e jurídicos, preservado o seu núcleo essencial.

De acordo com a explicação de uma possível colisão de princípios ou normas legais, o legislador deverá ponderar sobre uma dada realidade. De acordo com a tese do ministro Barroso (2009), no caso de decisão sobre a concessão de medicamentos de alto custo, não se deve verificar apenas a comprovação efetiva da hipossuficiência do cidadão requerente. Deve-se, ainda, levar em consideração a escassez dos recursos públicos, isto é, o intérprete da lei deve agir de forma razoável entre os limites dos princípios da Reserva do Possível e o do Mínimo Existencial, o que mais uma vez recai sobre a interpretação do magistrado.

Porém, de acordo com Farena (1997, p. 13):

As alegações de negativa de efetivação de um direito social com base no argumento da reserva do possível devem ser sempre analisadas com desconfiança. Não basta simplesmente alegar que não há possibilidades financeiras de se cumprir a ordem judicial; é preciso demonstrá-la. O que não se pode é deixar que a evocação da reserva do possível convertase em verdadeira razão de Estado econômico, num Al-5 econômico que opera, na verdade, como uma anti-Constituição, contra tudo o que a Carta consagra em matéria de direitos sociais.

Assim, cabe uma análise para se verificar como o intérprete da lei tem se comportado frente às necessidades dos cidadãos que convergem com os direitos fundamentais. Para identificar isso, será realizada uma análise a partir dos Acórdãos do STF nos anos de 2017 e 2018, nas matérias que tratam da concessão compulsória de medicamentos de alto custo. 


\section{ACÓRDÃO DO STF: UMA ANÁLISE DA CONCESSÃO DE MEDICAMENTOS DE ALTO CUSTO}

Após verificarmos que o Estado é responsável pela saúde do cidadão brasileiro enquanto direito fundamental, que nem sempre o direito pode ser executado tal qual está nos registros constitucionais (Reserva do Possível), cabe identificar como o STF agiu em relação aos seus Acórdãos referentes a concessão de medicamentos de alto custo.

Nos anos de 2017 e 2018 foram contabilizados 15 acórdãos. Dos 15 Acórdãos, somente 03 tiveram como agente requerente cidadãos em busca dos seus direitos. Dessa forma, privilegiou-se a análise dos Acórdãos que foram incitados por pessoas físicas.

Quadro 1 - Acórdãos x Relator x Decisão

\begin{tabular}{|l|l|l|l|l|}
\hline ANO & ACÓRDÃO & RELATOR & DECISÃO \\
\hline 2017 & $\begin{array}{l}\text { ARE 968012 } \\
\text { AgR / SP - SÃO }\end{array}$ & $\begin{array}{l}\text { Min. Ricardo } \\
\text { LAULO }\end{array}$ & $\begin{array}{l}\text { Negou o provimento. Ausência da } \\
\text { Comprovação de Hipossuficiência. }\end{array}$ \\
\hline 2017 & $\begin{array}{l}\text { ARE 1037265 A } \\
\text { GR / RN }\end{array}$ & Min. Dias Toffoli & $\begin{array}{l}\text { Negou o provimento. Medicamento em } \\
\text { fase experimental e não disponibilizado } \\
\text { pelo SUS. }\end{array}$ \\
\hline ARE 1065116 A & $\begin{array}{l}\text { Min. Cármen } \\
\text { Lúcia }\end{array}$ & $\begin{array}{l}\text { Negou provimento. O medicamento } \\
\text { não é disponibilizado pelo SUS. Há um } \\
\text { medicamento de igual eficácia } \\
\text { fornecido pelo SUS }\end{array}$ \\
\hline
\end{tabular}

Fonte: Dados coletados pela autora no site do STF

A partir do exposto no quadro 1, podemos observar que o STF se aproxima no primeiro Acórdão de uma decisão baseada em critérios do Princípio do Mínimo Existencial, em que há a necessidade de comprovação da hipossuficiência do cidadão agente 
requerente. O segundo e o terceiro Acórdão vão de encontro com a nossa hipótese, que discorre sobre o Princípio da Reserva do Possível, em que, decido pelo STF nega o provimento em caso de medicamentos em fase experimental e que esteja fora da lista, o que também enseja o não registro na ANVISA.

Os Acórdãos de Pernambuco e do Rio Grande do Norte não apresentam laudos técnicos sobre a eficácia do medicamento em fase experimental, assim como não considera o Princípio do Mínimo Existencial (isso no caso do RN). O de Pernambuco também não traz um laudo de eficácia sobre o medicamento solicitado, assim como a sua comparação técnica com o existente na lista do SUS, assim como também não traz um laudo de risco de vida e/ou saúde, isto é, desconsidera o mínimo existencial e superlativa o Princípio da Reserva do Possível, mesmo sem apresentar laudos técnicos sobre os orçamentos públicos.

\section{CONSIDERAÇÕES FINAIS}

A decisão do RE 657718, em maio de 2019 apresenta uma lista de exigências para se conceder um provimento no que tange à concessão de medicamentos de alto custo. Em tese, a conclusão proferida por maioria de votos e de Repercussão Geral alinha-se com o Princípio da Reserva do Possível, o que busca limitar os gastos do poder público com os medicamentos.

O nosso estudo demonstra, que mesmo antes da decisão do RE 657718, a partir da análise de três Acórdãos proferidos pelo STF entre os anos de 2017 e 2018, o Poder Judiciário, por meio de sua Suprema Corte Federal já tinha o entendimento que ora confirmou após uma espera de mais de dois anos. Demonstramos, ainda, que o STF tem se pautado pelo Princípio da Reserva do Possível, porém sem considerar a ponderação entre o Princípio do Mínimo Existencial, como propôs Alexy (2008) e Barroso (2009), pois os Acórdãos não trazem em seus conteúdos provas orçamentárias e ou mesmo de condições de vida do cidadão agente requerente.

Dessa monta, as nossas considerações finais se afinam com as análises de Farena (1997), que preceitua que ao privilegiar a reserva do possível em detrimento do 
mínimo existencial, instala-se um Estado Econômico e não garantidor dos direitos sociais. Essa constatação nos leva a observar que o direito à saúde, nessa questão específica, aqui estudada, é fruto de interpretação de juízes e do seus colegiados e não da lei, tal qual está na Constituição.

Por fim, tal exercício investigativo nos alerta para a necessidade dos nossos legisladores produzirem normas relativas e mais específicas no que tange ao direito à saúde, especialmente, a concessão de medicamentos de alto custo. Caso contrário a judicialização da saúde em larga escala tenderá a ser uma constante na realidade brasileira.

\section{REFERÊNCIAS}

ALEXY, R. Teoria dos direitos fundamentais. São Paulo: Malheiros, 2008.

BARROSO, L. R. Da falta de efetividade à judicialização excessiva: direito à saúde, fornecimento gratuito de medicamentos e parâmetros para a atuação judicial, 2009. Disponível em: <http://www.conjur.com.br/dl/estudobarroso.pdf>. Acesso em: 11.jul.2019.

BRASIL. Constituição Federal de 1988. In. Planalto Federal, 2019. Disponível em: < http://www.planalto.gov.br/ccivil_03/constituicao/constituicao.htm>. Acesso em: 05.jul.2019.

BRASIL. Política nacional de medicamentos. Brasília: Ministério da Saúde, 2001.

FARENA, D. V. M. A Saúde na Constituição Federal, p. 14. In: Boletim do Instituto Brasileiro de Advocacia Pública, n. 4, 1997, p. 12/14

HOIRISCH, C. Licença compulsória para medicamentos como política pública: o caso do antirretroviral Efavirenz. Rio de Janeiro: FGV, 2010. (Dissertação de Mestrado em Gestão Empresarial - FGV). 
RIBEIRO, L. M. Federalismo, Governo Local e Políticas Sociais no Brasil entre 1996 e 2004. In: HOCHMAN, Gilberto; FARIA, Carlos Aurélio Pimenta de (Org.). Federalismo e Políticas Públicas no Brasil. Rio de Janeiro: Editora Fiocruz, 2013.

SARLET, I. W. STJ, STF e os critérios para fornecimento de medicamentos (parte 1). Revista Consultor Jurídico, 27 de abril de 2018.

STF. Decisão do STF desobriga Estado de fornecer medicamento sem registro na $\quad 2019$ Anvisa, Disponível em: < http://www.stf.jus.br/portal/cms/verNoticiaDetalhe.asp?idConteudo=411857\&caixaBu sca $=\mathrm{N}$ >. Acesso em: 03.jul.2019.

VALLE, G. H. M. do; CAMARGO, J. M. P. A audiência pública sobre a judicialização da saúde e seus reflexos na jurisprudência do supremo tribunal federal. Revista de Direito Sanitário, v. 11, n. 3, p. 13-31, 2011.

VASCONCELOS FILHO, R. F. de. A judicialização da política de assistência farmacêutica do sistema único de saúde: o caso paradigmático do Supremo Tribunal Federal e a realidade regional do estado do Piauí. Teresina, UFPI, 2010. (Dissertação de Mestrado em Políticas Públicas - UFPI).

VIEIRA, F. S. Ações judiciais e direito à saúde: reflexão sobre a observância aos princípios do SUS. Revista de Saúde Pública, v. 42, p. 365-369, 2008.

Enviado: Novembro, 2020.

Aprovado: Dezembro, 2020. 